\title{
Detection of feline coronavirus spike gene mutations as a tool to diagnose feline infectious peritonitis
}

2017, Vol 19(4) 321-335

(C) The Author(s) 2015

Reprints and permissions:

sagepub.co.uk/journalsPermissions.nav DOI: $10.1177 / 1098612 \times 15623824$ journals.sagepub.com/home/jfms

(SSAGE

\section{Sandra Felten ${ }^{1}$, Karola Weider ${ }^{2}$, Stephanie Doenges ${ }^{1}$, Stefanie GruendI ${ }^{1}$, Kaspar Matiasek ${ }^{3}$, Walter Hermanns ${ }^{3}$, Elisabeth Mueller ${ }^{2}$, Lara Matiasek ${ }^{1}$, Andrea Fischer ${ }^{1}$, Karin Weber ${ }^{1}$, Johannes Hirschberger ${ }^{1}$, Gerhard Wess ${ }^{1}$ and Katrin Hartmann ${ }^{1}$}

\begin{abstract}
Objectives Feline infectious peritonitis (FIP) is an important cause of death in the cat population worldwide. The ante-mortem diagnosis of FIP in clinical cases is still challenging. In cats without effusion, a definitive diagnosis can only be achieved post mortem or with invasive methods. The aim of this study was to evaluate the use of a combined reverse transcriptase nested polymerase chain reaction (RT-nPCR) and sequencing approach in the diagnosis of FIP, detecting mutations at two different nucleotide positions within the spike (S) gene.

Methods The study population consisted of 64 cats with confirmed FIP and 63 cats in which FIP was initially suspected due to similar clinical or laboratory signs, but that were definitively diagnosed with another disease. Serum/plasma and/or effusion samples of these cats were examined for feline coronavirus (FCoV) RNA by RT-nPCR and, if positive, PCR products were sequenced for nucleotide transitions within the S gene.

Results Specificity of RT-nPCR was $100 \%$ in all materials (95\% confidence interval [Cl] in serum/plasma 83.9-100.0; 95\% Cl in effusion 93.0-100.0). The specificity of the sequencing step could not be determined as none of the cats of the control group tested positive for FCoV RNA. Sensitivity of the "combined RT-nPCR and sequencing approach' was 6.5\% (95\% Cl 0.8-21.4) in serum/plasma and 65.3\% (95\% Cl 50.4-78.3) in effusion. Conclusions and relevance A positive result is highly indicative of the presence of FIP, but as none of the control cats tested positive by RT-nPCR, it was not possible to confirm that the FCoV mutant described can only be found in cats with FIP. Further studies are necessary to evaluate the usefulness of the sequencing step including FCoVRNA-positive cats with and without FIP. A negative result cannot be used to exclude the disease, especially when only serum/plasma samples are available.
\end{abstract}

Accepted: 1 December 2015

\section{Introduction}

Feline infectious peritonitis (FIP) is a fatal immunemediated disease caused by infection with feline coronavirus (FCoV) that occurs worldwide. ${ }^{1} \mathrm{FCoV}$ exists as two distinct biotypes, the feline enteric coronavirus (FECV) and the feline infectious peritonitis virus (FIPV).2,3 Whereas antibodies against $\mathrm{FCoV}$ are very common in the cat population and prevalence can be as high as $90 \%$ in multi-cat households, FIP occurs in only approximately $5-10 \%$ of the FCoV-infected cats in multi-cat households. ${ }^{4-8}$ Regarding FIP pathogenesis, two different theories have been proposed. The 'circulating virulent and avirulent hypothesis' assumes that virulent and
${ }^{1}$ Clinic of Small Animal Medicine, Ludwig-Maximilians-University Munich, Munich, Germany

LABOKLIN GmbH \& Co KG, Bad Kissingen, Germany Institute of Veterinary Pathology, Centre for Clinical Veterinary Medicine, Ludwig-Maximilians-University Munich, Munich, Germany

\section{Corresponding author:}

Sandra Felten, Clinic of Small Animal Medicine, Ludwig-Maximilians-University Munich, Veterinaerstrasse 13, 80539 Munich, Germany

Email: sandra.felten@web.de 
avirulent FCoV strains coexist within the cat population. ${ }^{9,10}$ However, there is increasing evidence that FIP develops after spontaneous mutations of the genome of apathogenic FCoV within infected cats, which is referred to as the 'in vivo mutation hypothesis'. ${ }^{11,12}$ These mutations allow for sustained virus replication in macrophages, ${ }^{13}$ which is regarded as a key event in the pathogenesis of FIP. ${ }^{14,15}$

Several genes, including spike (S), $7 \mathrm{a}, 7 \mathrm{~b}$ and $3 \mathrm{c}$ genes have been discussed as sites for the mutations that are crucial for the pathotypic switch and changes in replication capacities in different cells. ${ }^{11,15-23}$ In contrast to previous studies, in which none of the sequence changes appeared to be consistently associated with the virulent FIPV variant, a recent study found nucleotide differences in two regions in close proximity in the $S$ gene (nucleotide 23531 and nucleotide 23537), that resulted in amino acid variations in the putative fusion peptide. These two mutations were correlated with the FIP phenotype in $>95 \%$ of cases. ${ }^{24}$ Considering the importance of the coronavirus $S$ protein fusion peptide in cell entry, ${ }^{25}$ these findings could reasonably explain the alteration in viral tropism. It was also shown that substitutions in a furin cleavage site within the $S$ protein of $F C o V$ can be detected in cats with confirmed FIP, which are likely leading to a modulation of proteolytic cleavage, thereby enhancing virus uptake in macrophages. ${ }^{26}$ However, systemic FCoVs with the above-mentioned spike gene mutations have been shown to occur also in cats without FIP. 24,27

Once the clinical disease FIP develops, it always leads to death within a few days or weeks, and there is no effective therapy available.28,29 Therefore, a definitive diagnosis ante-mortem is essential but often challenging. Presently, necropsy or immunostaining of FCoV antigen in effusion or tissue lesions obtained by laparotomy are considered the gold standard for the diagnosis of FIP.6,30,31 Immunostaining of fine-needle aspirations of lymph nodes or affected organs is also possible, but diagnostic sensitivity is very low. ${ }^{32}$ Thus, in cats without effusion, the definitive diagnosis can only be achieved with invasive laparotomy and biopsies of multiple organs, or might not be possible at all.

Several studies investigated the value of reverse transcriptase polymerase chain reaction (RT-PCR) in the diagnosis of FIP; however, the detection of FCoV RNA does not allow for differentiation between the virulent FIPV and avirulent FECV variant. Thus, conventional RT-PCR is also commonly positive in healthy cats that never will develop FIP.33-39 Detection of the mutated virus, however, could potentially be used to confirm the diagnosis ante-mortem.

Therefore, it was the aim of this study to evaluate the sensitivity and specificity of a combined approach using RT nested PCR (RT-nPCR) followed by sequencing, to detect two previously described mutations in the FCoV S gene in serum/plasma and effusion of cats suspected of having FIP. ${ }^{24}$ The combined approach was evaluated in cats with confirmed FIP and a defined control group of cats for which FIP was considered an important differential diagnosis by the clinician, thereby mimicking the real-life clinical situation. It was hypothesised that the combined RT-nPCR and sequencing approach, as it has recently become commercially available to veterinarians, would be a new non-invasive and reliable method to diagnose FIP definitively.

\section{Materials and methods}

\section{Animals}

Initially, 152 cats were included in the study. However, in 25 of these cats no definitive diagnosis was established and thus these 25 cats were excluded retrospectively. Consequently, the data of 127 cats with signs indicative of FIP, for which a conclusive diagnosis of either FIP or other diseases could be established, were included in the evaluation of sensitivity and specificity (Figure 1). Samples of all cats were investigated by RT-nPCR and sequencing by a person blinded to all data of the cats. Cats were presented either as patients of the Clinic of Small Animal Medicine $(n=101)$ or directly submitted for necropsy $(n=26)$ to the Institute of Veterinary Pathology, Ludwig-Maximilians-University Munich, Germany. According to their diagnoses, cats were categorised either in the FIP group or in the control group.

The FIP group $(n=64)$ consisted of cats with a definitive diagnosis of FIP (Table 1), established either by histopathology $(n=25)$, by histopathology plus immunohistochemical staining of FCoV antigen in tissue samples obtained at necropsy $(\mathrm{n}=28)^{40,41}$ or by a positive immunofluorescence staining of FCoV antigen in macrophages of effusions $(n=11) \cdot{ }^{34,42,43}$ In the cats with histopathological confirmation, diagnosis of FIP was achieved based on the occurrence of effusions and/or yellow to white foci or nodules in different organs plus the presence of typical histological lesions, including plasmacellular perivasculitis and/or accumulation of plasma cells with a necro-purulent centre. Typical lesions consisted of an arteriole or venule surrounded by a central area of necrosis that, in turn, was surrounded by proliferation macrophages and lymphocytes, plasma cells and neutrophils. ${ }^{44}$

Cats were included in the control group $(n=63)$ if clinicians suspected FIP due to one or more of the following signs consistent with FIP: effusion $(n=59)$, fever with $\leqslant 20,000$ white blood cells $/ \mu 1$ and $\leqslant 1000$ banded neutrophils $/ \mu \mathrm{l}(\mathrm{n}=2)$, icterus $(\mathrm{n}=6)$, neurological signs $(\mathrm{n}=5)$ or hyperglobulinaemia $(\mathrm{n}=1)$ (see Table 2$)$. Some cats showed several of these signs. Control cats were only included if they were definitively diagnosed with a disease other than FIP that explained the clinical signs 


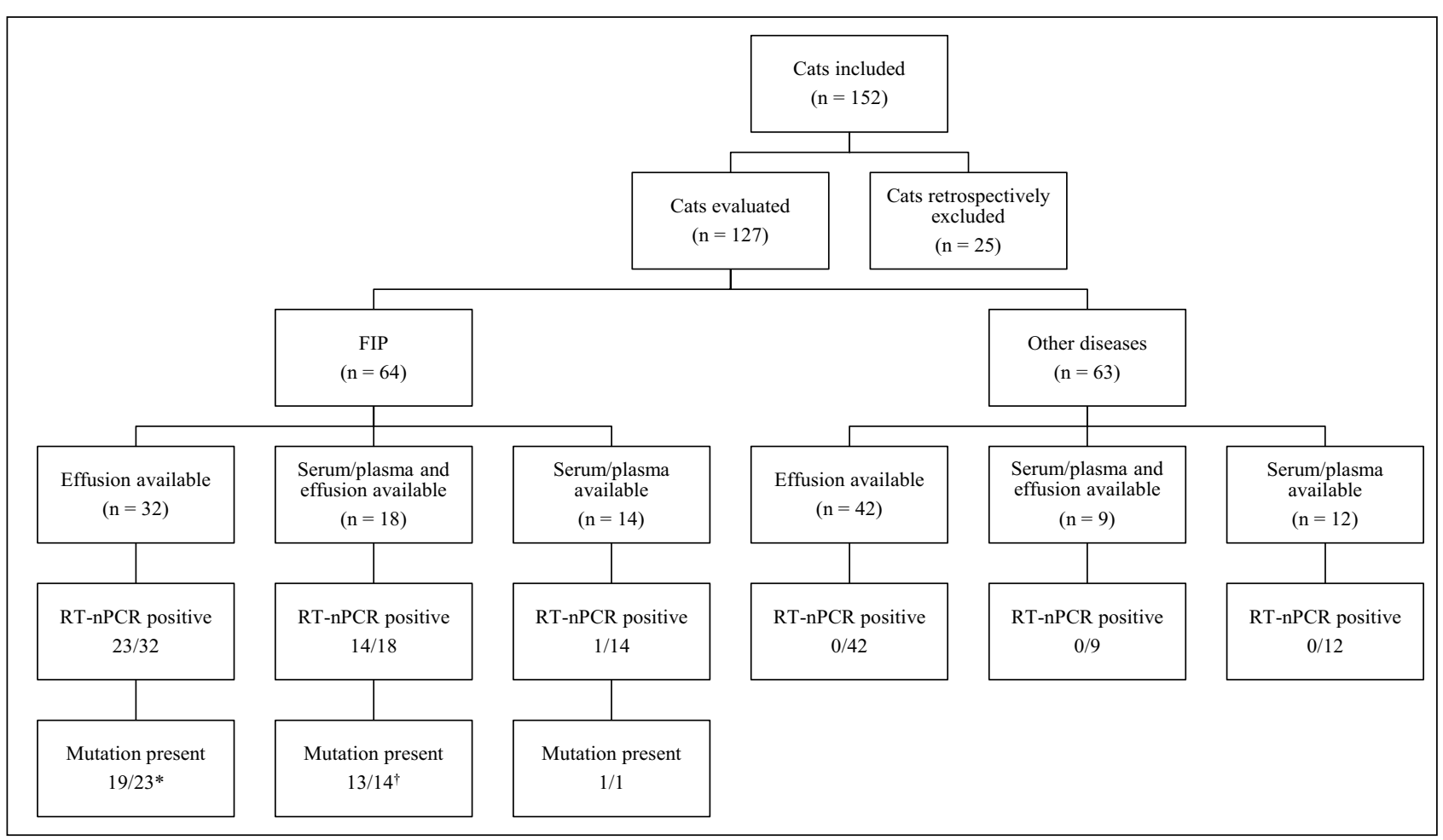

Figure 1 Flowchart illustrating total number of cats included in the study, available samples and results of the combined reverse transcriptase nested polymerase chain reaction (RT-nPCR) and sequencing approach. * In one cat, both a thymine ( $T$ [mutated]) and an adenine (A [non-mutated]) could be detected at position 23531. ${ }^{\text {tIn }}$ one cat, serum and effusion were tested positive by RT-nPCR and sequencing revealed two different mutations. FIP = feline infectious peritonitis

(Table 2). These other diseases were confirmed either by full post-mortem examination, including histopathology $(\mathrm{n}=28)$, by histopathology of organ samples obtained either post mortem $(n=1)$ or in laparotomy $(n=2)$, by cytology and bacterial culture diagnosing bacterial pleuritis or peritonitis $(n=2)$, by echocardiography, which identified decompensated cardiac disease explaining pleural or abdominal effusion $(n=16)$, or by cytology diagnosing neoplasia $(n=12)$. In addition, cats $(n=2)$ that survived $>3$ years after the beginning of the clinical signs listed above were included in the control group.

\section{Samples}

In total, 53 serum/plasma samples and 101 effusion samples were collected between 2009 and 2014. Blood was either stored as plasma ( $\mathrm{n}=14 ; 10$ cats with FIP, four control cats) at $-80{ }^{\circ} \mathrm{C}$ in a $2 \mathrm{ml}$ low-temperature freezer vial (VWR International) until assayed or as serum ( $\mathrm{n}=39 ; 22$ cats with FIP, 17 control cats) at $-20{ }^{\circ} \mathrm{C}$ in a $1.5 \mathrm{ml}$ Eppendorf Safe-Lock microcentrifuge tube until assayed. Effusion was collected (54 ascites, 46 pleural effusions, one pericardial effusion) and stored at $-80{ }^{\circ} \mathrm{C}$ in 55 cats ( 28 with FIP, 27 controls) or at $-20^{\circ} \mathrm{C}$ in 46 cats (22 with FIP, 24 controls) (Figure 1). All samples collected ante-mortem were originally obtained for diagnostic and, in the case of effusion, therapeutic purposes.

\section{PCR}

Nucleic acid was extracted from $200 \mu \mathrm{l}$ serum/plasma or effusion using the MagNA Pure 96 DNA and Viral NA Small Volume Kit (Roche) in conjunction with a MagNA Pure 96 Instrument (Roche), according to manufacturer's instructions. RT-nPCR was performed using specific primers for the $S$ gene region as previously described. ${ }^{24}$ RT-nPCR was done as a touchdown PCR using RealTime ready RNA Virus Master Kit (Roche) and FastStart Essential DNA Probes Master Kit (Roche). All enzymes and buffers were used according to the manufacturer's instructions. Touchdown cycling conditions were $15 \mathrm{mins}$ at $50^{\circ} \mathrm{C}$ and $10 \mathrm{mins}$ at $95^{\circ} \mathrm{C}$; followed by nine cycles of: $20 \mathrm{~s}$ at $95^{\circ} \mathrm{C}, 60 \mathrm{~s}$ at $62.5-54.5^{\circ} \mathrm{C}$ for the first round of RT-nPCR and $67.5-59.5^{\circ} \mathrm{C}$ for the second round (step-downs every nine cycles of $1^{\circ} \mathrm{C}$ ), and $45 \mathrm{~s}$ at $72^{\circ} \mathrm{C}$; followed by 30 cycles of $20 \mathrm{~s}$ at $95^{\circ} \mathrm{C}, 60 \mathrm{~s}$ at $54.5^{\circ} \mathrm{C}$ for the first round and $59.5^{\circ} \mathrm{C}$ for the second round, and $45 \mathrm{~s}$ at $72^{\circ} \mathrm{C}$; followed by a $7 \mathrm{~min}$ extension at $72^{\circ} \mathrm{C}$. All samples were examined for inhibition of the RT-nPCR. Inhibition was detected only in one effusion sample of a cat with cholangiohepatitis.

\section{DNA sequencing to detect the specific mutations}

PCR products were purified prior to sequencing using the Min Elute PCR Purification Kit (Qiagen). Sequencing was performed by cycle sequencing using DyeDeoxy 
Terminator Sequencing Kit (Applied Biosystems) in an automated sequencer ABI 3130 Genetic Analyzer (Applied Biosystems).

\section{Statistical evaluation}

Sensitivity, specificity, positive predictive value (PPV), negative predictive value (NPV), and overall accuracy (sum of true positive and true negative test results divided by the total number of test results) were calculated using a four-field chart. To quantify uncertainty, $95 \%$ confidence intervals (CI) were calculated. Statistical analysis was performed using MS Excel (Microsoft) and Prism Version 5.04 (GraphPad Software).

\section{Results}

The final study population consisted of 127 cats. Of these, 64 had FIP and 63 were included in the control group.

RT-nPCR of either serum/plasma and/or effusion detected FCoV in 38 cats; all of them had FIP. A mutation was found in $33 / 38$ of the PCR-positive cats. None of the 63 control cats tested positive by RT-nPCR (Figure 1). In two samples of the 38 RT-nPCR-positive cats, the sequence of the PCR product could not be determined; these samples were excluded from calculation of sensitivity, specificity, PPV, NPV and overall accuracy.

Table 1 Inclusion criteria, method of confirmation of diagnosis, available samples and results of the combined reverse transcriptase nested polymerase chain reaction (RT-nPCR) and sequencing approach for cats of the feline infectious peritonitis (FIP) group

\begin{tabular}{|c|c|c|c|c|c|c|c|}
\hline Cat & $\begin{array}{l}\text { Clincal signs leading } \\
\text { to inclusion }\end{array}$ & Diagnosis & $\begin{array}{l}\text { Method of confirmation } \\
\text { of disease }\end{array}$ & $\begin{array}{l}\text { Samples } \\
\text { available }\end{array}$ & $\begin{array}{l}\text { Result of } \\
\text { RT-nPCR } \\
\text { of serum/ } \\
\text { plasma } \\
\text { samples }\end{array}$ & $\begin{array}{l}\text { Result } \\
\text { of RT- } \\
\text { nPCR of } \\
\text { effusion } \\
\text { samples }\end{array}$ & $\begin{array}{l}\text { Detected } \\
\text { nucleotide } \\
\text { change }\end{array}$ \\
\hline 1 & $\begin{array}{l}\text { Pleural effusion, fever, } \\
\text { uveitis }\end{array}$ & FIP & $\begin{array}{l}\text { Histopathology plus } \\
\text { immunohistochemistry }\end{array}$ & Effusion & ND & Positive & 23531-T \\
\hline 2 & Pleural effusion & FIP & $\begin{array}{l}\text { Histopathology plus } \\
\text { immunohistochemistry }\end{array}$ & Effusion & ND & Negative & ND \\
\hline 3 & Ascites, icterus & FIP & $\begin{array}{l}\text { Histopathology plus } \\
\text { immunohistochemistry }\end{array}$ & Effusion & ND & Positive & 23531- $\mathrm{T}$ \\
\hline 4 & Ascites, icterus & FIP & $\begin{array}{l}\text { Histopathology plus } \\
\text { immunohistochemistry }\end{array}$ & Effusion & ND & Positive & 23531- $\mathrm{T}$ \\
\hline 5 & Ascites, fever, icterus & FIP & $\begin{array}{l}\text { Histopathology plus } \\
\text { immunohistochemistry }\end{array}$ & Effusion & ND & Positive & 23531- $\mathrm{T}$ \\
\hline 6 & Ascites, fever, icterus & FIP & $\begin{array}{l}\text { Histopathology plus } \\
\text { immunohistochemistry }\end{array}$ & Effusion & ND & Positive & None \\
\hline 7 & Ascites, icterus & FIP & $\begin{array}{l}\text { Histopathology plus } \\
\text { immunohistochemistry }\end{array}$ & Effusion & ND & Negative & ND \\
\hline 8 & $\begin{array}{l}\text { Ascites, neurological } \\
\text { signs, uveitis }\end{array}$ & FIP & $\begin{array}{l}\text { Histopathology plus } \\
\text { immunohistochemistry }\end{array}$ & Effusion & ND & Positive & 23531- $\mathrm{T}$ \\
\hline 9 & $\begin{array}{l}\text { Ascites, } \\
\text { hyperglobulinaemia }\end{array}$ & FIP & $\begin{array}{l}\text { Immunofluorescence } \\
\text { staining of FCoV antigen } \\
\text { in macrophages }\end{array}$ & Effusion & ND & Negative & ND \\
\hline 10 & Ascites & FIP & $\begin{array}{l}\text { Histopathology plus } \\
\text { immunohistochemistry }\end{array}$ & Effusion & ND & Positive & 23531- $\mathrm{T}$ \\
\hline 11 & Pleural effusion & FIP & $\begin{array}{l}\text { Histopathology plus } \\
\text { immunohistochemistry }\end{array}$ & Effusion & ND & Positive & 23531-T \\
\hline 12 & Ascites & FIP & $\begin{array}{l}\text { Histopathology plus } \\
\text { immunohistochemistry }\end{array}$ & Effusion & ND & Negative & ND \\
\hline 13 & $\begin{array}{l}\text { Ascites, icterus, } \\
\text { hyperglobulinaemia }\end{array}$ & FIP & $\begin{array}{l}\text { Histopathology plus } \\
\text { immunohistochemistry }\end{array}$ & $\begin{array}{l}\text { Plasma } \\
\text { and } \\
\text { effusion }\end{array}$ & Negative & Positive & 23531- $T$ \\
\hline 14 & $\begin{array}{l}\text { Fever, icterus, } \\
\text { neurological signs, } \\
\text { hyperglobulinaemia }\end{array}$ & FIP & $\begin{array}{l}\text { Histopathology plus } \\
\text { immunohistochemistry }\end{array}$ & Plasma & Negative & ND & ND \\
\hline 15 & Ascites, icterus & FIP & $\begin{array}{l}\text { Histopathology plus } \\
\text { immunohistochemistry }\end{array}$ & Effusion & ND & Positive & 23531- $\mathrm{T}$ \\
\hline 16 & Ascites & FIP & $\begin{array}{l}\text { Histopathology plus } \\
\text { immunohistochemistry }\end{array}$ & Effusion & ND & Negative & ND \\
\hline
\end{tabular}


Table 1 (Continued)

\begin{tabular}{|c|c|c|c|c|c|c|c|}
\hline Cat & $\begin{array}{l}\text { Clincal signs leading } \\
\text { to inclusion }\end{array}$ & Diagnosis & $\begin{array}{l}\text { Method of confirmation } \\
\text { of disease }\end{array}$ & $\begin{array}{l}\text { Samples } \\
\text { available }\end{array}$ & $\begin{array}{l}\text { Result of } \\
\text { RT-nPCR } \\
\text { of serum/ } \\
\text { plasma } \\
\text { samples }\end{array}$ & $\begin{array}{l}\text { Result } \\
\text { of RT- } \\
\text { nPCR of } \\
\text { effusion } \\
\text { samples }\end{array}$ & $\begin{array}{l}\text { Detected } \\
\text { nucleotide } \\
\text { change }\end{array}$ \\
\hline 17 & $\begin{array}{l}\text { Ascites, fever, icterus, } \\
\text { hyperglobulinaemia }\end{array}$ & FIP & $\begin{array}{l}\text { Histopathology plus } \\
\text { immunohistochemistry }\end{array}$ & $\begin{array}{l}\text { Plasma } \\
\text { and } \\
\text { effusion }\end{array}$ & Negative & Negative & ND \\
\hline 18 & $\begin{array}{l}\text { Ascites, fever, } \\
\text { hyperglobulinaemia, } \\
\text { uveitis }\end{array}$ & FIP & $\begin{array}{l}\text { Histopathology plus } \\
\text { immunohistochemistry }\end{array}$ & $\begin{array}{l}\text { Plasma } \\
\text { and } \\
\text { effusion }\end{array}$ & Negative & Negative & ND \\
\hline 19 & $\begin{array}{l}\text { Ascites, icterus, } \\
\text { neurological signs, } \\
\text { hyperglobulinaemia }\end{array}$ & FIP & $\begin{array}{l}\text { Histopathology plus } \\
\text { immunohistochemistry }\end{array}$ & $\begin{array}{l}\text { Plasma } \\
\text { and } \\
\text { effusion }\end{array}$ & Negative & Positive & 23531-T \\
\hline 20 & Ascites, fever, icterus & FIP & $\begin{array}{l}\text { Histopathology plus } \\
\text { immunohistochemistry }\end{array}$ & Effusion & ND & Positive & 23531- $\mathrm{T}$ \\
\hline 21 & $\begin{array}{l}\text { Ascites, fever, } \\
\text { hyperglobulinaemia }\end{array}$ & FIP & $\begin{array}{l}\text { Histopathology plus } \\
\text { immunohistochemistry }\end{array}$ & $\begin{array}{l}\text { Plasma } \\
\text { and } \\
\text { effusion }\end{array}$ & Negative & Positive & 23531-T \\
\hline 22 & $\begin{array}{l}\text { Pleural effusion, fever, } \\
\text { hyperglobulinaemia }\end{array}$ & FIP & $\begin{array}{l}\text { Histopathology plus } \\
\text { immunohistochemistry }\end{array}$ & $\begin{array}{l}\text { Plasma } \\
\text { and } \\
\text { effusion }\end{array}$ & Negative & Positive & 23531- $T$ \\
\hline 23 & Ascites & FIP & $\begin{array}{l}\text { Histopathology plus } \\
\text { immunohistochemistry }\end{array}$ & $\begin{array}{l}\text { Plasma } \\
\text { and } \\
\text { effusion }\end{array}$ & Negative & Positive & 23537-G \\
\hline 24 & Ascites & FIP & $\begin{array}{l}\text { Histopathology plus } \\
\text { immunohistochemistry }\end{array}$ & Effusion & ND & Negative & ND \\
\hline 25 & Ascites & FIP & $\begin{array}{l}\text { Histopathology plus } \\
\text { immunohistochemistry }\end{array}$ & $\begin{array}{l}\text { Plasma } \\
\text { and } \\
\text { effusion }\end{array}$ & Negative & Negative & ND \\
\hline 26 & Ascites, icterus & FIP & $\begin{array}{l}\text { Histopathology plus } \\
\text { immunohistochemistry }\end{array}$ & $\begin{array}{l}\text { Plasma } \\
\text { and } \\
\text { effusion }\end{array}$ & Negative & Positive & 23531-T \\
\hline 27 & $\begin{array}{l}\text { Ascites, icterus, } \\
\text { hyperglobulinaemia }\end{array}$ & FIP & $\begin{array}{l}\text { Histopathology plus } \\
\text { immunohistochemistry }\end{array}$ & Effusion & ND & Positive & 23531- $\mathrm{T}$ \\
\hline 28 & Ascites, icterus & FIP & $\begin{array}{l}\text { Histopathology plus } \\
\text { immunohistochemistry }\end{array}$ & Effusion & ND & Positive & $23531-\mathrm{T}$ \\
\hline 29 & $\begin{array}{l}\text { Ascites, icterus, } \\
\text { hyperglobulinaemia }\end{array}$ & FIP & $\begin{array}{l}\text { Histopathology plus } \\
\text { immunohistochemistry }\end{array}$ & Effusion & ND & Positive & 23531-T \\
\hline 30 & $\begin{array}{l}\text { Ascites and pleural } \\
\text { effusion, icterus }\end{array}$ & FIP & Histopathology & Serum & Negative & ND & ND \\
\hline 31 & $\begin{array}{l}\text { Ascites, fever, } \\
\text { hyperglobulinaemia }\end{array}$ & FIP & $\begin{array}{l}\text { Immunofluorescence } \\
\text { staining of FCoV antigen } \\
\text { in macrophages }\end{array}$ & $\begin{array}{l}\text { Serum } \\
\text { and } \\
\text { effusion }\end{array}$ & Negative & Positive & 23531-T \\
\hline 32 & Ascites, fever, icterus & FIP & $\begin{array}{l}\text { Immunofluorescence } \\
\text { staining of FCoV antigen } \\
\text { in macrophages }\end{array}$ & Serum & Negative & ND & ND \\
\hline 33 & $\begin{array}{l}\text { Icterus, } \\
\text { hyperglobulinaemia }\end{array}$ & FIP & Histopathology & Serum & Negative & ND & ND \\
\hline 34 & $\begin{array}{l}\text { Ascites, icterus, } \\
\text { neurological signs, } \\
\text { hyperglobulinaemia }\end{array}$ & FIP & Histopathology & Serum & Positive & ND & 23537-G \\
\hline 35 & Hyperglobulinaemia & FIP & Histopathology & Serum & Negative & ND & ND \\
\hline 36 & $\begin{array}{l}\text { Ascites, fever, } \\
\text { hyperglobulinaemia, } \\
\text { uveitis }\end{array}$ & FIP & Histopathology & $\begin{array}{l}\text { Serum } \\
\text { and } \\
\text { effusion }\end{array}$ & Negative & Negative & ND \\
\hline
\end{tabular}


Table 1 (Continued)

\begin{tabular}{|c|c|c|c|c|c|c|c|}
\hline Cat & $\begin{array}{l}\text { Clincal signs leading } \\
\text { to inclusion }\end{array}$ & Diagnosis & $\begin{array}{l}\text { Method of confirmation } \\
\text { of disease }\end{array}$ & $\begin{array}{l}\text { Samples } \\
\text { available }\end{array}$ & $\begin{array}{l}\text { Result of } \\
\text { RT-nPCR } \\
\text { of serum/ } \\
\text { plasma } \\
\text { samples }\end{array}$ & $\begin{array}{l}\text { Result } \\
\text { of RT- } \\
\text { nPCR of } \\
\text { effusion } \\
\text { samples }\end{array}$ & $\begin{array}{l}\text { Detected } \\
\text { nucleotide } \\
\text { change }\end{array}$ \\
\hline 37 & $\begin{array}{l}\text { Ascites, icterus, } \\
\text { neurological signs, } \\
\text { hyperglobulinaemia }\end{array}$ & FIP & Histopathology & Serum & Negative & ND & ND \\
\hline 38 & Ascites & FIP & Histopathology & Serum & Negative & ND & ND \\
\hline 39 & $\begin{array}{l}\text { Ascites, icterus, } \\
\text { hyperglobulinaemia }\end{array}$ & FIP & Histopathology & $\begin{array}{l}\text { Serum } \\
\text { and } \\
\text { effusion }\end{array}$ & Negative & Positive & 23531- $\mathrm{T}$ \\
\hline 40 & Pleural effusion, fever & FIP & $\begin{array}{l}\text { Immunofluorescence } \\
\text { staining of FCoV antigen } \\
\text { in macrophages }\end{array}$ & $\begin{array}{l}\text { Serum } \\
\text { and } \\
\text { effusion }\end{array}$ & Negative & Positive & 23531- $\mathrm{T}$ \\
\hline 41 & Ascites, fever, icterus & FIP & $\begin{array}{l}\text { Immunofluorescence } \\
\text { staining of FCoV antigen } \\
\text { in macrophages }\end{array}$ & Serum & Negative & ND & ND \\
\hline 42 & Pleural effusion, fever & FIP & Histopathology & $\begin{array}{l}\text { Serum } \\
\text { and } \\
\text { effusion }\end{array}$ & Negative & Positive & 23531- $\mathrm{T}$ \\
\hline 43 & Ascites, icterus & FIP & Histopathology & Serum & Negative & ND & ND \\
\hline 44 & $\begin{array}{l}\text { Pleural effusion, fever, } \\
\text { hyperglobulinaemia }\end{array}$ & FIP & Histopathology & Serum & Negative & ND & ND \\
\hline 45 & $\begin{array}{l}\text { Ascites, fever, icterus, } \\
\text { hyperglobulinaemia }\end{array}$ & FIP & $\begin{array}{l}\text { Immunofluorescence } \\
\text { staining of FCoV antigen } \\
\text { in macrophages }\end{array}$ & $\begin{array}{l}\text { Serum } \\
\text { and } \\
\text { effusion }\end{array}$ & Negative & Positive & 23531- $\mathrm{T}$ \\
\hline 46 & Pleural effusion & FIP & $\begin{array}{l}\text { Immunofluorescence } \\
\text { staining of FCoV antigen } \\
\text { in macrophages }\end{array}$ & Serum & Negative & ND & ND \\
\hline 47 & Ascites, icterus & FIP & Histopathology & Serum & Negative & ND & ND \\
\hline 48 & $\begin{array}{l}\text { Pleural effusion, } \\
\text { icterus }\end{array}$ & FIP & Histopathology & $\begin{array}{l}\text { Serum } \\
\text { and } \\
\text { effusion }\end{array}$ & Positive & Negative & $\begin{array}{l}\text { Sequence } \\
\text { could not be } \\
\text { determined }\end{array}$ \\
\hline 49 & Pleural effusion & FIP & $\begin{array}{l}\text { Immunofluorescence } \\
\text { staining of FCoV antigen } \\
\text { in macrophages }\end{array}$ & $\begin{array}{l}\text { Serum } \\
\text { and } \\
\text { effusion }\end{array}$ & Negative & Positive & 23531- $\mathrm{T}$ \\
\hline 50 & $\begin{array}{l}\text { Ascites, neurological } \\
\text { signs }\end{array}$ & FIP & Histopathology & Serum & Negative & ND & ND \\
\hline 51 & Pleural effusion & FIP & Histopathology & Effusion & ND & Negative & ND \\
\hline 52 & Ascites, fever, icterus & FIP & Histopathology & Effusion & ND & Positive & 23531-C \\
\hline 53 & Ascites, fever & FIP & Histopathology & Effusion & ND & Positive & None \\
\hline 54 & Ascites, fever & FIP & $\begin{array}{l}\text { Immunofluorescence } \\
\text { staining of FCoV antigen } \\
\text { in macrophages }\end{array}$ & Effusion & ND & Positive & $\begin{array}{l}23531-T \text { and } \\
23531-A\end{array}$ \\
\hline 55 & Ascites & FIP & $\begin{array}{l}\text { Immunofluorescence } \\
\text { staining of FCoV antigen } \\
\text { in macrophages }\end{array}$ & Effusion & ND & Positive & None \\
\hline 56 & Ascites, fever & FIP & Histopathology & Effusion & ND & Positive & 23537-G \\
\hline 57 & $\begin{array}{l}\text { Ascites, icterus, } \\
\text { neurological signs }\end{array}$ & FIP & Histopathology & Effusion & ND & Negative & ND \\
\hline 58 & Ascites, icterus & FIP & Histopathology & Effusion & ND & Positive & $\begin{array}{l}\text { Sequence } \\
\text { could not be } \\
\text { determined }\end{array}$ \\
\hline 59 & $\begin{array}{l}\text { Ascites, icterus, } \\
\text { hyperglobulinaemia }\end{array}$ & FIP & Histopathology & Effusion & ND & Positive & 23531- $\mathrm{T}$ \\
\hline 60 & Ascites, fever, icterus & FIP & Histopathology & Effusion & ND & Positive & 23531- \\
\hline
\end{tabular}


Table 1 (Continued)

\begin{tabular}{|c|c|c|c|c|c|c|c|}
\hline Cat & $\begin{array}{l}\text { Clincal signs leading } \\
\text { to inclusion }\end{array}$ & Diagnosis & $\begin{array}{l}\text { Method of confirmation } \\
\text { of disease }\end{array}$ & $\begin{array}{l}\text { Samples } \\
\text { available }\end{array}$ & $\begin{array}{l}\text { Result of } \\
\text { RT-nPCR } \\
\text { of serum/ } \\
\text { plasma } \\
\text { samples }\end{array}$ & $\begin{array}{l}\text { Result } \\
\text { of RT- } \\
\text { nPCR of } \\
\text { effusion } \\
\text { samples }\end{array}$ & $\begin{array}{l}\text { Detected } \\
\text { nucleotide } \\
\text { change }\end{array}$ \\
\hline 61 & Ascites, fever, icterus & FIP & $\begin{array}{l}\text { Immunofluorescence } \\
\text { staining of FCoV antigen } \\
\text { in macrophages }\end{array}$ & Effusion & ND & Positive & 23531- $T$ \\
\hline 62 & Ascites & FIP & Histopathology & Effusion & ND & Positive & 23531-C \\
\hline 63 & Ascites, icterus & FIP & Histopathology & Effusion & ND & Negative & ND \\
\hline 64 & Ascites, icterus & FIP & Histopathology & $\begin{array}{l}\text { Serum } \\
\text { and } \\
\text { effusion }\end{array}$ & Positive & Positive & $\begin{array}{l}\text { 23531-T } \\
\text { (effusion) } \\
\text { 23531-C } \\
\text { (serum) }\end{array}$ \\
\hline
\end{tabular}

$\mathrm{ND}=$ not determined; $\mathrm{T}$ = thymine; $\mathrm{FCoV}=$ feline coronavirus; $\mathrm{G}=$ guanine; $\mathrm{C}=$ cytosine; $\mathrm{A}=$ adenine

Table 2 Inclusion criteria, definitive diagnosis, method of confirmation of diagnosis, available samples and results of the combined reverse transcriptase nested polymerase chain reaction (RT-nPCR) and sequencing approach for cats of the control group

\begin{tabular}{|c|c|c|c|c|c|c|c|}
\hline Cat & $\begin{array}{l}\text { Clinical signs } \\
\text { leading to } \\
\text { inclusion }\end{array}$ & Diagnosis & $\begin{array}{l}\text { Method of } \\
\text { confirmation } \\
\text { of disease }\end{array}$ & $\begin{array}{l}\text { Samples } \\
\text { available }\end{array}$ & $\begin{array}{l}\text { Result of } \\
\text { RT-nPCR } \\
\text { of serum/ } \\
\text { plasma } \\
\text { samples }\end{array}$ & $\begin{array}{l}\text { Result of } \\
\text { RT-nPCR } \\
\text { of effusion } \\
\text { samples }\end{array}$ & $\begin{array}{l}\text { Detected } \\
\text { nucleotide } \\
\text { change }\end{array}$ \\
\hline 1 & Ascites & $\begin{array}{l}\text { Pancreatitis/ } \\
\text { hepatic lipidosis }\end{array}$ & Histopathology & Effusion & ND & Negative & ND \\
\hline 2 & Pericardial effusion & $\begin{array}{l}\text { Bacterial myo- } \\
\text { and epicarditis }\end{array}$ & Histopathology & Effusion & ND & Negative & ND \\
\hline 3 & $\begin{array}{l}\text { Pleural effusion, } \\
\text { neurological signs }\end{array}$ & $\begin{array}{l}\text { Chronic kidney } \\
\text { disease, } \\
\text { hypertensive } \\
\text { encephalopathy; } \\
\text { effusion most } \\
\text { likely due to } \\
\text { hypervolaemia }\end{array}$ & Histopathology & Effusion & ND & Negative & ND \\
\hline 4 & Ascites & $\begin{array}{l}\text { Chronic kidney } \\
\text { disease; effusion } \\
\text { most likely due to } \\
\text { hypervolaemia }\end{array}$ & Histopathology & Effusion & ND & Negative & ND \\
\hline 5 & $\begin{array}{l}\text { Ascites, } \\
\text { neurological signs }\end{array}$ & $\begin{array}{l}\text { Enteritis/ } \\
\text { cholangiohepatitis }\end{array}$ & Histopathology & Effusion & ND & Negative & ND \\
\hline 6 & Ascites & $\begin{array}{l}\text { Persistent foramen } \\
\text { ovale }\end{array}$ & Histopathology & Effusion & ND & Negative & ND \\
\hline 7 & Pleural effusion & Angiosarcoma & Histopathology & Effusion & ND & Negative & ND \\
\hline 8 & Pleural effusion & $\begin{array}{l}\text { Decompensated } \\
\text { cardiac disease }\end{array}$ & Echocardiography & Effusion & ND & Negative & ND \\
\hline 9 & Pleural effusion & $\begin{array}{l}\text { Decompensated } \\
\text { cardiac disease }\end{array}$ & Echocardiography & Effusion & ND & Negative & ND \\
\hline 10 & Ascites & $\begin{array}{l}\text { Invasive } \\
\text { pancreatic } \\
\text { adenocarcinoma }\end{array}$ & $\begin{array}{l}\text { Histopathology } \\
\text { of organ samples } \\
\text { (obtained } \\
\text { post mortem) }\end{array}$ & Effusion & ND & Negative & ND \\
\hline 11 & Pleural effusion & $\begin{array}{l}\text { Pulmonary } \\
\text { adenocarcinoma }\end{array}$ & Histopathology & Effusion & ND & Negative & ND \\
\hline 12 & Pleural effusion & Bacterial pleuritis & $\begin{array}{l}\text { Bacterial culture } \\
\text { and cytology }\end{array}$ & Effusion & ND & Negative & ND \\
\hline
\end{tabular}


Table 2 (Continued)

\begin{tabular}{|c|c|c|c|c|c|c|c|}
\hline Cat & $\begin{array}{l}\text { Clinical signs } \\
\text { leading to } \\
\text { inclusion }\end{array}$ & Diagnosis & $\begin{array}{l}\text { Method of } \\
\text { confirmation } \\
\text { of disease }\end{array}$ & $\begin{array}{l}\text { Samples } \\
\text { available }\end{array}$ & $\begin{array}{l}\text { Result of } \\
\text { RT-nPCR } \\
\text { of serum/ } \\
\text { plasma } \\
\text { samples }\end{array}$ & $\begin{array}{l}\text { Result of } \\
\text { RT-nPCR } \\
\text { of effusion } \\
\text { samples }\end{array}$ & $\begin{array}{l}\text { Detected } \\
\text { nucleotide } \\
\text { change }\end{array}$ \\
\hline 13 & Ascites & Lymphoma & Histopathology & $\begin{array}{l}\text { Plasma } \\
\text { and } \\
\text { effusion }\end{array}$ & Negative & Negative & ND \\
\hline 14 & Pleural effusion & $\begin{array}{l}\text { Decompensated } \\
\text { cardiac disease }\end{array}$ & Echocardiography & Effusion & ND & Negative & ND \\
\hline 15 & Pleural effusion & $\begin{array}{l}\text { Decompensated } \\
\text { cardiac disease }\end{array}$ & Echocardiography & Effusion & ND & Negative & ND \\
\hline 16 & Pleural effusion & Lymphoma & Histopathology & Effusion & ND & Negative & ND \\
\hline 17 & $\begin{array}{l}\text { Pleural effusion, } \\
\text { neurological signs }\end{array}$ & $\begin{array}{l}\text { Pulmonary } \\
\text { carcinoma }\end{array}$ & Histopathology & $\begin{array}{l}\text { Plasma } \\
\text { and } \\
\text { effusion }\end{array}$ & Negative & Negative & ND \\
\hline 18 & Pleural effusion & $\begin{array}{l}\text { Chronic } \\
\text { cardiomyopathy }\end{array}$ & Histopathology & Effusion & ND & Negative & ND \\
\hline 19 & Fever, icterus & Cholangiohepatitis & Histopathology & Plasma & Negative & ND & ND \\
\hline 20 & Pleural effusion & $\begin{array}{l}\text { Pulmonary } \\
\text { adenocarcinoma }\end{array}$ & Histopathology & Effusion & ND & Negative & ND \\
\hline 21 & Pleural effusion & $\begin{array}{l}\text { Decompensated } \\
\text { cardiac disease }\end{array}$ & Echocardiography & Effusion & ND & Negative & ND \\
\hline 22 & Pleural effusion & $\begin{array}{l}\text { Sarcoma of } \\
\text { lung, pleura, } \\
\text { mediastinum }\end{array}$ & Histopathology & $\begin{array}{l}\text { Serum } \\
\text { and } \\
\text { effusion }\end{array}$ & Negative & Negative & ND \\
\hline 23 & Neurological signs & Lymphoma & Histopathology & Serum & Negative & ND & ND \\
\hline 24 & Ascites & $\begin{array}{l}\text { Chronic fibrosing } \\
\text { gastritis, chronic } \\
\text { eosinophilic } \\
\text { enteritis, } \\
\text { protein-losing } \\
\text { enteropathy; } \\
\text { effusion most } \\
\text { likely due to low } \\
\text { oncotic pressure }\end{array}$ & $\begin{array}{l}\text { Histopathology } \\
\text { of organ samples } \\
\text { (obtained in } \\
\text { laparotomy) }\end{array}$ & Serum & Negative & ND & ND \\
\hline 25 & $\begin{array}{l}\text { Icterus, neurological } \\
\text { signs }\end{array}$ & $\begin{array}{l}\text { Necrotising } \\
\text { polioencephalitis, } \\
\text { hepatic lipidosis }\end{array}$ & Histopathology & Serum & Negative & ND & ND \\
\hline 26 & Pleural effusion & $\begin{array}{l}\text { Decompensated } \\
\text { cardiac disease }\end{array}$ & Echocardiography & Effusion & ND & Negative & ND \\
\hline 27 & $\begin{array}{l}\text { Ascites and pleural } \\
\text { effusion }\end{array}$ & $\begin{array}{l}\text { Acute renal } \\
\text { failure; effusion } \\
\text { most likely due to } \\
\text { vasculitis }\end{array}$ & $\begin{array}{l}\text { History, } \\
\text { biochemistry, } \\
\text { ultrasonography, } \\
\text { survival time }>3 \\
\text { years }\end{array}$ & Serum & Negative & ND & ND \\
\hline 28 & Pleural effusion & $\begin{array}{l}\text { Decompensated } \\
\text { cardiac disease }\end{array}$ & Echocardiography & Effusion & ND & Negative & ND \\
\hline 29 & Pleural effusion & $\begin{array}{l}\text { Decompensated } \\
\text { cardiac disease }\end{array}$ & Echocardiography & $\begin{array}{l}\text { Serum } \\
\text { and } \\
\text { effusion }\end{array}$ & Negative & Negative & ND \\
\hline 30 & Pleural effusion & Lymphoma & Histopathology & Serum & Negative & ND & ND \\
\hline 31 & Icterus & Lymphoma & Histopathology & Serum & Negative & ND & ND \\
\hline 32 & Pleural effusion & $\begin{array}{l}\text { Decompensated } \\
\text { cardiac disease }\end{array}$ & Echocardiography & Effusion & ND & Negative & ND \\
\hline 33 & Ascites & $\begin{array}{l}\text { Decompensated } \\
\text { cardiac disease }\end{array}$ & Echocardiography & Effusion & ND & Negative & ND \\
\hline
\end{tabular}


Table 2 (Continued)

\begin{tabular}{|c|c|c|c|c|c|c|c|}
\hline Cat & $\begin{array}{l}\text { Clinical signs } \\
\text { leading to } \\
\text { inclusion }\end{array}$ & Diagnosis & $\begin{array}{l}\text { Method of } \\
\text { confirmation } \\
\text { of disease }\end{array}$ & $\begin{array}{l}\text { Samples } \\
\text { available }\end{array}$ & $\begin{array}{l}\text { Result of } \\
\text { RT-nPCR } \\
\text { of serum/ } \\
\text { plasma } \\
\text { samples }\end{array}$ & $\begin{array}{l}\text { Result of } \\
\text { RT-nPCR } \\
\text { of effusion } \\
\text { samples }\end{array}$ & $\begin{array}{l}\text { Detected } \\
\text { nucleotide } \\
\text { change }\end{array}$ \\
\hline 34 & Pleural effusion & $\begin{array}{l}\text { Decompensated } \\
\text { cardiac disease }\end{array}$ & Echocardiography & Effusion & ND & Negative & ND \\
\hline 35 & $\begin{array}{l}\text { Ascites, } \\
\text { hyperglobulinaemia }\end{array}$ & $\begin{array}{l}\text { Chronic } \\
\text { cholangiohepatitis }\end{array}$ & $\begin{array}{l}\text { Histopathology } \\
\text { of organ samples } \\
\text { (obtained in } \\
\text { laparotomy) }\end{array}$ & Serum & Negative & ND & ND \\
\hline 36 & $\begin{array}{l}\text { Ascites and pleural } \\
\text { effusion }\end{array}$ & $\begin{array}{l}\text { Bronchoalveolar } \\
\text { carcinoma }\end{array}$ & Histopathology & Serum & Negative & ND & ND \\
\hline 37 & Ascites, icterus & Lymphoma & Histopathology & Serum & Negative & ND & ND \\
\hline 38 & Pleural effusion & $\begin{array}{l}\text { Chronic nephritis } \\
\text { and enteritis; } \\
\text { effusion most } \\
\text { likely due to } \\
\text { hypervolaemia }\end{array}$ & Histopathology & Effusion & ND & Negative & ND \\
\hline 39 & Pleural effusion & Pulmonary fibrosis & Histopathology & Effusion & ND & Negative & ND \\
\hline 40 & Pleural effusion & $\begin{array}{l}\text { Decompensated } \\
\text { cardiac disease }\end{array}$ & Echocardiography & Effusion & ND & Negative & ND \\
\hline 41 & Ascites & $\begin{array}{l}\text { Hepatic } \\
\text { cystadenoma } \\
\text { with fibrinous } \\
\text { fibroblastic } \\
\text { peritonitis, chronic } \\
\text { kidney disease }\end{array}$ & Histopathology & Effusion & ND & Negative & ND \\
\hline 42 & Pleural effusion & $\begin{array}{l}\text { Bronchial } \\
\text { carcinoma }\end{array}$ & Histopathology & Effusion & ND & Negative & ND \\
\hline 43 & Pleural effusion & $\begin{array}{l}\text { Decompensated } \\
\text { cardiac disease }\end{array}$ & Echocardiography & Serum & Negative & ND & ND \\
\hline 44 & Pleural effusion & $\begin{array}{l}\text { Chronic pleural } \\
\text { chylous effusion } \\
\text { of unknown origin } \\
\text { and secondary } \\
\text { fibroblastic } \\
\text { pleuritis }\end{array}$ & Histopathology & Effusion & ND & Negative & ND \\
\hline 45 & Pleural effusion & $\begin{array}{l}\text { Pulmonary } \\
\text { adenocarcinoma }\end{array}$ & Histopathology & Effusion & ND & Negative & ND \\
\hline 46 & Ascites, fever & $\begin{array}{l}\text { Bacterial } \\
\text { peritonitis }\end{array}$ & Histopathology & Effusion & ND & Negative & ND \\
\hline 47 & Ascites & $\begin{array}{l}\text { Bacterial } \\
\text { peritonitis, } \\
\text { ruptured splenic } \\
\text { abscess }\end{array}$ & $\begin{array}{l}\text { Bacterial culture } \\
\text { and cytology }\end{array}$ & Effusion & ND & Negative & ND \\
\hline 48 & Pleural effusion & $\begin{array}{l}\text { Decompensated } \\
\text { cardiac disease }\end{array}$ & Echocardiography & Effusion & ND & Negative & ND \\
\hline 49 & Pleural effusion & $\begin{array}{l}\text { Decompensated } \\
\text { cardiac disease }\end{array}$ & Echocardiography & Effusion & ND & Negative & ND \\
\hline 50 & Pleural effusion & $\begin{array}{l}\text { Decompensated } \\
\text { cardiac disease }\end{array}$ & Echocardiography & Effusion & ND & Negative & ND \\
\hline 51 & Ascites & $\begin{array}{l}\text { Obstructive feline } \\
\text { lower urinary tract } \\
\text { disease; effusion } \\
\text { most likely due } \\
\text { to concurrent } \\
\text { peritonitis }\end{array}$ & $\begin{array}{l}\text { History, } \\
\text { ultrasonography, } \\
\text { survival time }>3 \\
\text { years }\end{array}$ & Serum & Negative & ND & ND \\
\hline
\end{tabular}


Table 2 (Continued)

\begin{tabular}{|c|c|c|c|c|c|c|c|}
\hline Cat & $\begin{array}{l}\text { Clinical signs } \\
\text { leading to } \\
\text { inclusion }\end{array}$ & Diagnosis & $\begin{array}{l}\text { Method of } \\
\text { confirmation } \\
\text { of disease }\end{array}$ & $\begin{array}{l}\text { Samples } \\
\text { available }\end{array}$ & $\begin{array}{l}\text { Result of } \\
\text { RT-nPCR } \\
\text { of serum/ } \\
\text { plasma } \\
\text { samples }\end{array}$ & $\begin{array}{l}\text { Result of } \\
\text { RT-nPCR } \\
\text { of effusion } \\
\text { samples }\end{array}$ & $\begin{array}{l}\text { Detected } \\
\text { nucleotide } \\
\text { change }\end{array}$ \\
\hline 52 & Pleural effusion & Lymphoma & Cytology & Effusion & ND & Negative & ND \\
\hline 53 & Pleural effusion & Carcinoma & Cytology & Effusion & ND & Negative & ND \\
\hline 54 & Ascites & Carcinoma & Cytology & Effusion & ND & Negative & ND \\
\hline 55 & Pleural effusion & Lymphoma & Cytology & $\begin{array}{l}\text { Plasma } \\
\text { and } \\
\text { effusion }\end{array}$ & Negative & Negative & ND \\
\hline 56 & Pleural effusion & Carcinoma & Cytology & $\begin{array}{l}\text { Serum } \\
\text { and } \\
\text { effusion }\end{array}$ & Negative & Negative & ND \\
\hline 57 & $\begin{array}{l}\text { Pleural effusion, } \\
\text { icterus }\end{array}$ & Lymphoma & Cytology & $\begin{array}{l}\text { Serum } \\
\text { and } \\
\text { effusion }\end{array}$ & Negative & Negative & ND \\
\hline 58 & Pleural effusion & Carcinoma & Cytology & $\begin{array}{l}\text { Serum } \\
\text { and } \\
\text { effusion }\end{array}$ & Negative & Negative & ND \\
\hline 59 & Ascites & Carcinoma & Cytology & Effusion & ND & Negative & ND \\
\hline 60 & Pleural effusion & Lymphoma & Cytology & $\begin{array}{l}\text { Serum } \\
\text { and } \\
\text { effusion }\end{array}$ & Negative & Negative & ND \\
\hline 61 & $\begin{array}{l}\text { Pleural effusion, } \\
\text { icterus }\end{array}$ & $\begin{array}{l}\text { Malignant round } \\
\text { cell tumour }\end{array}$ & Cytology & Effusion & ND & Negative & ND \\
\hline 62 & Ascites & Lymphoma & Cytology & Effusion & ND & Negative & ND \\
\hline 63 & Pleural effusion & $\begin{array}{l}\text { Malignant round } \\
\text { cell tumour }\end{array}$ & Cytology & Effusion & ND & Negative & ND \\
\hline
\end{tabular}

$N D=$ not determined

Table 3 Results of the combined reverse transcriptase nested polymerase chain reaction (RT-nPCR) and sequencing approach in serum/plasma samples $(n=53)$

\begin{tabular}{lllllll} 
Group & Negative RT-nPCR & Positive RT-nPCR & $\begin{array}{l}\text { Total number of } \\
\text { samples with mutation }\end{array}$ & $\begin{array}{l}\text { Mutation 23531-T/ } \\
23531-C\end{array}$ & $\begin{array}{c}\text { Mutation } \\
23537-G\end{array}$ & Total \\
\hline FIP & 29 & 3 & $2^{*}$ & $1(0 / 1)$ & 1 & 32 \\
Controls & 21 & 0 & ND & ND & ND & 21 \\
Total & 50 & 3 & $2^{*}$ & $1(0 / 1)$ & 1 & 53 \\
\hline
\end{tabular}

$\mathrm{T}=$ thymine; $\mathrm{C}=$ cytosine; $\mathrm{G}=$ guanine; FIP = feline infectious peritonitis; ND = not determined

*For the third PCR-positive sample, the sequence could not be determined

Table 4 Results of the combined reverse transcriptase nested polymerase chain reaction (RT-nPCR) and sequencing approach in effusion samples $(n=101)$

\begin{tabular}{lllllll} 
Group & Negative RT-nPCR & Positive RT-nPCR & $\begin{array}{l}\text { Total number of } \\
\text { samples with mutation }\end{array}$ & $\begin{array}{l}\text { Mutation 23531-T/ } \\
23531-\mathrm{C}\end{array}$ & $\begin{array}{c}\text { Mutation } \\
23537-\mathrm{G}\end{array}$ & Total \\
\hline FIP & 14 & 36 & 32 & $30(28 / 2)$ & 2 & 50 \\
Controls & 51 & 0 & ND & ND & ND & 51 \\
Total & 65 & 36 & 32 & $30(28 / 2)$ & 2 & 101 \\
\hline
\end{tabular}

$\mathrm{T}=$ thymine $\mathrm{C}=$ cytosine; $\mathrm{G}=$ guanine; $\mathrm{FIP}=$ feline infectious peritonitis; $\mathrm{ND}=$ not determined 
Table 5 Results of the combined reverse transcriptase nested polymerase chain reaction (RT-nPCR) and sequencing approach in 52 serum/plasma samples (one serum sample was excluded because sequencing was not possible)

\begin{tabular}{llll} 
& FIP & Control & Total \\
\hline Positive & 2 & 0 & 2 \\
Negative & 29 & 21 & 50 \\
Total & 31 & 21 & 52
\end{tabular}

FIP = feline infectious peritonitis
Table 6 Results of the combined reverse transcriptase nested polymerase chain reaction (RT-nPCR) and sequencing approach in 100 effusion samples (one sample was excluded because sequencing was not possible)

\begin{tabular}{llll} 
& FIP & Control & Total \\
\hline Positive & 32 & 0 & 32 \\
Negative & 17 & 51 & 68 \\
Total & 49 & 51 & 100
\end{tabular}

FIP = feline infectious peritonitis

Table 7 Results of the combined reverse transcriptase nested polymerase chain reaction (RT-nPCR) and sequencing approach in serum/plasma and effusion samples, and prevalence of feline infectious peritonitis (FIP) in 152 samples of 125 cats (one serum and one effusion sample were excluded because sequencing was not possible). Sensitivity refers to the RT-nPCR plus sequencing; specificity only refers to the RT-nPCR. Specificity of the sequencing step could not be determined because no cats of the control group were positive in the RT-nPCR

\begin{tabular}{lll} 
& Serum/plasma & Effusion \\
\hline Sensitivity & $6.5(0.8-21.4)$ & $65.3(50.4-78.3)$ \\
Specificity & $100.0(83.9-100.0)$ & $100.0(93.0-100.0)$ \\
Positive predictive value & $100.0(15.8-100.0)$ & $100.0(89.1-100.0)$ \\
Negative predictive value & $42.0(28.2-56.8)$ & $75.0(63.0-84.7)$ \\
Overall accuracy & $44.2(30.5-58.7)$ & $83.0(74.2-89.8)$ \\
Prevalence & $59.6^{*}$ & $49.0^{\dagger}$
\end{tabular}

Data are $\%$ (95\% confidence interval)

*Prevalence of FIP in cats for which serum/plasma was available (number of cats with FIP divided by the number of all cats for which serum/ plasma was available)

tPrevalence of FIP in cats for which effusion was available (number of cats with FIP divided by the number of all cats for which effusion was available)

Of the 53 serum/plasma samples investigated, three tested positive by RT-nPCR; $2 / 3$ had one of the two mutations in the $\mathrm{S}$ gene. For the third PCR-positive serum/plasma sample, no sequence could be determined. Of the 101 effusion samples, 36 tested positive by RT-nPCR; mutations were found in 32/36 of these PCR-positive samples (Tables 1-4). Sensitivity, specificity, PPV, NPV and overall accuracy are shown in Tables 5-7.

Two of the 25 cats that had to be excluded retrospectively tested positive by RT-nPCR. In one cat with suspected bacterial pleuritis (cytology of pleural effusion was suggestive of bacterial pleuritis, but bacterial culture was negative), FCoV-RNA was found in effusion by RT-nPCR, but sequencing did not detect a mutation. In another cat with suspected renal carcinoma (cytology of renal aspirate was suggestive of renal carcinoma but full-body necropsy and histopathology were not available and therefore the cat was excluded), RT-nPCR was positive in plasma and sequencing detected a mutation at position 23531.

Both serum/plasma and effusion samples were examined in 27 cats. In 12 of them, RT-nPCR plus sequencing was positive in effusion but negative in serum/plasma.
In one cat, RT-nPCR plus sequencing was negative in effusion, while RT-nPCR was weakly positive in serum, but the sequence could not be determined. For another cat, serum, as well as effusion, gave a positive result by RT-nPCR plus sequencing.

Of the 33 cats with positive sequencing, in 30 an adenine $(\mathrm{A}) \rightarrow$ thymine $(\mathrm{T})$ or $\mathrm{A} \rightarrow$ cytosine $(\mathrm{C})$ transition at position 23531 was detected. In three cats, a $\mathrm{T} \rightarrow$ guanine (G) transition at position 23537 was identified. Two cats exhibited two different nucleotides at the critical sites. In one of these cats, sequencing revealed both a $T$ (mutated) and an A (non-mutated) at position 23531 in effusion. In the other cat, mutation 23531-T was found in effusion, while 23531-C was detected in serum.

\section{Discussion}

The aim of this study was to determine the diagnostic value of a combined RT-nPCR and sequencing approach in the diagnosis of FIP. FCoVs are separated into two different serotypes depending on growth characteristics in cell culture and on their relationship to canine coronavirus. ${ }^{45-47}$ Serotypes were not differentiated in the present study, as this is not of clinical relevance, because both 
serotypes can cause FIP. Therefore, it is possible that cats with FIP caused by type II FCoV were not detected in the present study.

This is the first study evaluating this approach in serum/plasma and effusion of cats that were presented with clinical signs typical of FIP. Thus, the strength of this study is that it mimics the real-life situation in which a clinician would submit a diagnostic sample to diagnose FIP. Diagnostic specificity of the RT-nPCR was very high in both serum/plasma and effusion; however, the specificity of the combined approach including the sequencing step could not be determined owing to the lack of control cats that were positive for FCoV in the RT-nPCR. Diagnostic sensitivity was $65.3 \%$ in effusion and only $6.5 \%$ in serum/plasma.

In a recent study, tissue and faecal samples of cats with and without FIP were examined with a quantitative RT-PCR and pyrosequencing. ${ }^{27} \mathrm{~A}$ total of 112 tissue and faecal samples of 27 cats with immunohistochemically confirmed FIP and 16 control cats were directly compared. The authors found that nucleotide changes at position 23531 of the $S$ gene resulting in amino acid differences at position 1058 of the predicted spike protein did not correlate with FIP disease phenotype. Both leucine (resulting from a $\mathrm{T}$ or $\mathrm{C}$ at position 23531) and methionine (resulting from an A at position 23531) codons were found in cats with and without FIP. A leucine codon was found not only in the majority (91\%) of tissue samples of cats with FIP, but also in the majority $(89 \%)$ of tissue samples of cats with other diseases. Additionally, a significant number $(9 \%)$ of tissue samples from cats with FIP contained a methionine codon at position 1058. The authors therefore suggest that the M1058L substitution is a marker of systemic spread of FCoV rather than of FIP phenotype. However, in 2012 Chang et al found a M1058L point mutation only in cats with FIP. ${ }^{24}$ A second substitution (S1060A, resulting from the nucleotide change at position 23537) was described by Chang et al to detect a further $4 \%$ of FIP cases. ${ }^{24}$

Specificity in the present study was $100 \%$, indicating that the combined RT-nPCR and sequencing approach is a valuable tool to confirm FIP. Interestingly, also the RT-nPCR by itself, even without sequencing, had the same high specificity. Nevertheless, as none of the control cats tested positive by RT-nPCR, a real control group for the sequencing was missing in the present study. Therefore, diagnostic specificity actually could only be determined for the RT-nPCR alone, and not for the combined approach. It is surprising that none of the finally included control cats was FCoV-viraemic and this raises the question of whether sequencing was necessary at all. Several studies investigated the use of RT-PCR assays as diagnostic tools and revealed rather low specificities. ${ }^{33-36,48,49}$ However, some of these studies used healthy cats originating from shelters or catteries as control group. In contrast in the present study, cats in the control group showed signs consistent with FIP, thus reflecting the population of cats presented to a veterinary practice in which a clinician would regard FIP as a differential diagnosis. The risk of $\mathrm{FCoV}$ infection increases in multi-cat environments. ${ }^{50-52}$ Unfortunately, the investigated control cat population without FIP in the present study did not include any FCoV-viraemic cats. Owing to this limitation the combined RT-nPCR and sequencing approach could not be evaluated in FCoV-viraemic cats without FIP that might be presented to a veterinary practice. Therefore, and therefore it could not be proven that FCoV with $S$ gene mutations occur only in cats with FIP. If these mutations really are a marker for systemic spread of the virus rather than for FIP phenotype, ${ }^{27}$ then it is possible that the test specificity would have been lower with a different study population.

Twenty-five cats were retrospectively excluded from the study because a definitive diagnosis could not be established when following very strict criteria. One of these cats was suspected of having bacterial pleuritis and effusion tested positive in RT-nPCR, but no mutation was detected. It is likely that the cat was viraemic with an apathogenic FECV that extravasated from blood into the body cavity. The existence of viraemia in FCoVinfected cats without FIP has previously been described, ${ }^{35,36,53}$ and inflammation of serosal surfaces might have led to leakage of blood components, including FCoV. Another cat was suspected of having renal carcinoma. The plasma of this cat was positive by RT-nPCR, and sequencing revealed a mutation at position 23531 . It is possible that the cat was infected with an apathogenic FCoV and exhibited a mutation due to systemic spread of that virus rather than due to FIP. ${ }^{27}$ Nevertheless, it cannot be excluded that the cat suffered from FIP instead of, or additionally to, the carcinoma.

The sensitivity of the combined RT-nPCR and sequencing approach in the present study was low. Sequencing of the PCR product was negative or not possible in only five of the 38 PCR-positive cats, which most likely was a result of a low virus load in the samples. Therefore, the RT-nPCR was mainly responsible for the low sensitivity and not the sequencing, even though the RT-nPCR was performed as touchdown PCR, which is known to have a higher sensitivity than the conventional PCR. ${ }^{54}$ If the sensitivity of the PCR technique used had been too low, then positive PCR results could have been missed, also in cats without FIP. One possible explanation for the low sensitivity is likely a low virus load in the samples. The very low sensitivity of the approach in serum/plasma samples is in contrast to previous studies, detecting higher sensitivities of approximately $60-81 \%$ when investigating blood components. $35,36,49$ Monocytes/macrophages are the target cells for viral replication. ${ }^{14,40,55,56}$ Although serum and plasma have been commonly used, it is therefore possible that the 
sensitivity might have been higher in whole blood. Nevertheless, even whole blood has been recently identified as a poor sample type. ${ }^{57,58}$ In the present study, sensitivity was much better in effusion than serum/plasma. This indicates that cats with FIP exhibit much higher virus loads in effusion than in blood, ${ }^{58}$ although in a study testing RT-PCR in ascites from cats clinically suspected of having FIP, virus was detected in only $377 / 854$ cats $(44.1 \%) .{ }^{59}$ In these cats, however, FIP was not definitively confirmed. In the present study, which included only cats with FIP confirmed by gold standard methods, $36 / 50$ cats with FIP (72\%) tested positive by RT-nPCR.

The overall accuracy was calculated as the sum of true positive and true negative test results divided by the total number of test results, thereby being a marker for the overall diagnostic performance of the combined RT-nPCR and sequencing approach. Especially when using serum/plasma, the usefulness of the test is limited, as the overall accuracy was only $44.2 \%$. Owing to the better diagnostic sensitivity, overall accuracy of the approach was much higher in effusion samples, reaching $83.0 \%$.

As all samples collected ante-mortem were only obtained if needed for diagnostic and/or therapeutic purposes, the prevalence of FIP among the groups varied. Of the cats from which serum/plasma was available, $59.6 \%$ suffered from FIP, whereas $49.0 \%$ of the cats from which effusion was available had FIP. In a previous study, the prevalence of FIP was higher in cats with effusion $(51 \%)$ compared with cats without effusion $(28 \%))^{34}$

One of the cats with FIP had two different mutations in serum and in effusion (23531-T in effusion, 23531-C in serum). Another cat with FIP showed signals of two different nucleotides at position 23531 upon sequencing of the PCR products in effusion. In this cat, both a $\mathrm{T}$ (mutated) and an A (non-mutated) were detected. It is possible that these cats were co-infected with two distinct FCoV variants. Previous studies have reported the existence of different virus strains within the same cat at the same time. ${ }^{19,27,60}$ As FIPVs likely arise by individual mutation from $F E C V, 11,12$ it is possible that the two variants evolved as independent mutations from one single parental virus.

In three cats with FIP, sequencing did not detect the mutations, although RT-nPCR was positive. It is possible that other critical mutations also lead to the development of FIP. A recent study compared FECV and FIPV sequences with regard to variations in a furin cleavage site in the region between receptor-binding (S1) and fusion (S2) domains of the spike gene and indeed found functional S1/S2 cleavage site mutations that were strongly correlated with FIP. ${ }^{26}$

One limitation of this study was that in several cats only one sample type (serum/plasma or effusion) was available. Serum/plasma samples could not be obtained in already dead cats submitted directly for necropsy; on the other hand, some of the cats did not have effusions. Another limitation was that blood was only available either as plasma or serum, and whole blood might have given better sensitivities. In some of the cats of the FIP group, the diagnosis was established by a positive immunofluorescence staining of $\mathrm{FCoV}$ antigen in macrophages of effusions. A recently published study detected a specificity of only $71.4 \%$ for a direct immunofluorescence test. ${ }^{61}$ In view of these results, it might seem possible that inclusion of cats with false-positive immunofluorescence test results into the FIP group has occurred, which might have decreased sensitivity of the combined RT-nPCR and sequencing approach.

\section{Conclusions}

This study evaluated the use of a combined RT-nPCR and sequencing approach in the diagnosis of FIP. Specificity and PPV of the RT-nPCR were $100 \%$ in serum/plasma and effusion specimens. Diagnostic specificity of the combined approach including RT-nPCR and sequencing could not be determined because no cats of the control group were positive in the RT-nPCR. Nevertheless, this result should be interpreted cautiously, as one cat with suspected renal carcinoma, that was retrospectively excluded from the study population, likely showed a false-positive test result. Sensitivity of the approach was rather low, with effusion yielding a much better result than serum/plasma. Therefore, a negative test result can never rule out FIP. The lack of sensitivity when using serum/plasma is disappointing, as this approach was considered especially important to test cats without effusions. Nevertheless, in the case of FIP, which is a fatal disease, specificity is the most important diagnostic parameter. A diagnostic specificity of near to $100 \%$ would prevent euthanasia of cats that were misdiagnosed with FIP due to false-positive test results. However, as none of the control cats were tested positive for FCoV in the RT-nPCR in this study, further studies are requested to evaluate the usefulness of the sequencing step in a control group with cats that test positive by RT-nPCR for the non-mutated virus.

Acknowledgements We would like to thank Prof Dr Herman F Egberink, Department of Infectious Diseases and Immunology, Utrecht University, for fruitful discussions.

Conflict of interest Dr Elisabeth Mueller is the Managing Director of Laboklin GmbH \& Co KG. Dr Karola Weider is employed at Laboklin GmbH \& Co KG. This laboratory offered the combined RT-nPCR and sequencing approach on a commercial basis and performed the testing in this study.

Funding The authors received no financial support for the research, authorship, and/or publication of this article. 


\section{References}

1 Pedersen NC. Coronavirus diseases (coronavirus enteritis, feline infectious peritonitis). In: Holzworth J (ed). Diseases of the cat medicine and surgery. Philadelphia, PA: Saunders, 1987, pp 193-214.

2 Pedersen N, Boyle J and Floyd K. Infection studies in kittens, using feline infectious peritonitis virus propagated in cell culture. Am J Vet Res 1981; 42: 363-367.

3 Pedersen NC. Virologic and immunologic aspects of feline infectious peritonitis virus infection. Adv Exp Med Biol 1987; 218: 529-550.

4 Pedersen NC. Serologic studies of naturally occurring feline infectious peritonitis. Am J Vet Res 1976; 37: 1449-1453.

5 Sparkes AH, Gruffydd-Jones TJ, Howard PE, et al. Coronavirus serology in healthy pedigree cats. Vet Rec 1992; 131: 35-36.

6 Kipar A and Meli ML. Feline infectious peritonitis: still an enigma? Vet Pathol 2014; 51: 505-526.

7 Drechsler Y, Alcaraz A, Bossong FJ, et al. Feline coronavirus in multicat environments. Vet Clin North Am Small Anim Pract 2011; 41: 1133-1169.

8 Addie DD, Toth S, Murray GD, et al. Risk of feline infectious peritonitis in cats naturally infected with feline coronavirus. Am J Vet Res 1995; 56: 429-434.

9 Brown MA, Troyer JL, Pecon-Slattery J, et al. Genetics and pathogenesis of feline infectious peritonitis virus. Emerg Infect Dis 2009; 15: 1445-1452.

10 Dye $C$ and Siddell SG. Genomic RNA sequence of feline coronavirus strain FCoV C1Je. J Feline Med Surg 2007; 9: 202-213.

11 Vennema H, Poland A, Foley J, et al. Feline infectious peritonitis viruses arise by mutation from endemic feline enteric coronaviruses. Virology 1998; 243: 150-157.

12 Poland AM, Vennema H, Foley JE, et al. Two related strains of feline infectious peritonitis virus isolated from immunocompromised cats infected with a feline enteric coronavirus. J Clin Microbiol 1996; 34: 3180-3184.

13 Dewerchin HL, Cornelissen E and Nauwynck HJ. Replication of feline coronaviruses in peripheral blood monocytes. Arch Virol 2005; 150: 2483-2500.

14 Stoddart CA and Scott FW. Intrinsic resistance of feline peritoneal macrophages to coronavirus infection correlates with in vivo virulence. J Virol 1989; 63: 436-440.

15 Rottier PJ, Nakamura K, Schellen P, et al. Acquisition of macrophage tropism during the pathogenesis of feline infectious peritonitis is determined by mutations in the feline coronavirus spike protein. J Virol 2005; 79: 14122-14130.

16 Kennedy M, Boedeker N, Gibbs P, et al. Deletions in the 7 a ORF of feline coronavirus associated with an epidemic of feline infectious peritonitis. Vet Microbiol 2001; 81: 227-234.

17 Pedersen NC, Liu H, Dodd KA, et al. Significance of coronavirus mutants in feces and diseased tissues of cats suffering from feline infectious peritonitis. Viruses 2009; 1 : 166-184.

18 Haijema BJ, Volders $\mathrm{H}$ and Rottier PJ. Live, attenuated coronavirus vaccines through the directed deletion of group-specific genes provide protection against feline infectious peritonitis. J Virol 2004; 78: 3863-3871.
19 Chang HW, de Groot RJ, Egberink HF, et al. Feline infectious peritonitis: insights into feline coronavirus pathobiogenesis and epidemiology based on genetic analysis of the viral 3c gene. J Gen Virol 2010; 91: 415-420.

20 Takano T, Tomiyama Y, Katoh Y, et al. Mutation of neutralizing/antibody-dependent enhancing epitope on spike protein and $7 \mathrm{~b}$ gene of feline infectious peritonitis virus: influences of viral replication in monocytes/macrophages and virulence in cats. Virus Res 2011; 156: 72-80.

21 Pedersen NC, Liu H, Scarlett J, et al. Feline infectious peritonitis: role of the feline coronavirus $3 c$ gene in intestinal tropism and pathogenicity based upon isolates from resident and adopted shelter cats. Virus Res 2012; 165: 17-28.

22 Bank-Wolf BR, Stallkamp I, Wiese S, et al. Mutations of $3 c$ and spike protein genes correlate with the occurrence of feline infectious peritonitis. Vet Microbiol 2014; 173 : 177-188.

23 Borschensky CM and Reinacher M. Mutations in the $3 \mathrm{c}$ and $7 \mathrm{~b}$ genes of feline coronavirus in spontaneously affected FIP cats. Res Vet Sci 2014; 97: 333-340.

24 Chang HW, Egberink HF, Halpin R, et al. Spike protein fusion peptide and feline coronavirus virulence. Emerg Infect Dis 2012; 18: 1089-1095.

25 Bosch BJ, van der Zee R, de Haan CA, et al. The coronavirus spike protein is a class $I$ virus fusion protein: structural and functional characterization of the fusion core complex. J Virol 2003; 77: 8801-8811.

26 Licitra BN, Millet JK, Regan AD, et al. Mutation in spike protein cleavage site and pathogenesis of feline coronavirus. Emerg Infect Dis 2013; 19: 1066-1073.

27 Porter E, Tasker S, Day MJ, et al. Amino acid changes in the spike protein of feline coronavirus correlate with systemic spread of virus from the intestine and not with feline infectious peritonitis. Vet Res 2014; 45: 49-59.

28 Fischer Y, Ritz S, Weber K, et al. Randomized, placebo controlled study of the effect of propentofylline on survival time and quality of life of cats with feline infectious peritonitis. J Vet Intern Med 2011; 25: 1270-1276.

29 Ritz S, Egberink H and Hartmann K. Effect of feline interferon-omega on the survival time and quality of life of cats with feline infectious peritonitis. J Vet Intern Med 2007; 21: 1193-1197.

30 Addie DD, Paltrinieri S and Pedersen NC. Recommendations from workshops of the second international feline coronavirus/feline infectious peritonitis symposium. J Feline Med Surg 2004; 6: 125-130.

31 Pedersen NC. A review of feline infectious peritonitis virus infection: 1963-2008. J Feline Med Surg 2009; 11: 225-258.

32 Giordano A, Paltrinieri S, Bertazzolo W, et al. Sensitivity of Tru-cut and fine needle aspiration biopsies of liver and kidney for diagnosis of feline infectious peritonitis. Vet Clin Pathol 2005; 34: 368-374.

33 Can-Sahna K, Soydal Ataseven V, Pinar D, et al. The detection of feline coronaviruses in blood samples from cats by mRNA RT-PCR. J Feline Med Surg 2007; 9: 369-372.

34 Hartmann K, Binder C, Hirschberger J, et al. Comparison of different tests to diagnose feline infectious peritonitis. J Vet Intern Med 2003; 17: 781-790.

35 Herrewegh AA, de Groot RJ, Cepica A, et al. Detection of feline coronavirus RNA in feces, tissues, and body fluids 
of naturally infected cats by reverse transcriptase PCR. J Clin Microbiol 1995; 33: 684-689.

36 Gunn-Moore DA, Gruffydd-Jones TJ and Harbour DA. Detection of feline coronaviruses by culture and reverse transcriptase-polymerase chain reaction of blood samples from healthy cats and cats with clinical feline infectious peritonitis. Vet Microbiol 1998; 62: 193-205.

37 Sharif S, Arshad SS, Hair-Bejo M, et al. Evaluation of feline coronavirus viraemia in clinically healthy and ill cats with feline infectious peritonitis. J Anim Vet Adv 2011; 10: 18-22.

38 Pedersen NC. An update on feline infectious peritonitis: diagnostics and therapeutics. Vet J 2014; 201: 133-141.

39 Kennedy MA, Brenneman K, Millsaps RK, et al. Correlation of genomic detection of feline coronavirus with various diagnostic assays for feline infectious peritonitis. J Vet Diagn Invest 1998; 10: 93-97.

40 Kipar A, Bellmann S, Kremendahl J, et al. Cellular composition, coronavirus antigen expression and production of specific antibodies in lesions in feline infectious peritonitis. Vet Immunol Immunopathol 1998; 65: 243-257.

41 Tammer R, Evensen $\mathrm{O}$, Lutz $\mathrm{H}$, et al. Immunohistological demonstration of feline infectious peritonitis virus antigen in paraffin-embedded tissues using feline ascites or murine monoclonal antibodies. Vet Immunol Immunopathol 1995; 49: 177-182.

42 Paltrinieri S, Parodi MC and Cammarata G. In vivo diagnosis of feline infectious peritonitis by comparison of protein content, cytology, and direct immunofluorescence test on peritoneal and pleural effusions. J Vet Diagn Invest 1999; 11: 358-361.

43 Parodi MC, Cammarata G, Paltrinieri S, et al. Using direct immunofluorescence to detect coronaviruses in peritoneal in peritoneal and pleural effusions. J Small Anim Pract 1993; 34: 609-613.

44 Addie DD and Jarrett $\mathrm{O}$. Feline coronavirus infection. In: Greene CE (ed). Infectious diseases of the dog and cat. Philadelphia, PA: WB Saunders, 1990, pp 58-69.

45 Herrewegh AA, Smeenk I, Horzinek MC, et al. Feline coronavirus type II strains 79-1683 and 79-1146 originate from a double recombination between feline coronavirus type I and canine coronavirus. J Virol 1998; 72: 4508-4514.

46 Hohdatsu T, Sasamoto T, Okada S, et al. Antigenic analysis of feline coronaviruses with monoclonal antibodies (MAbs): preparation of MAbs which discriminate between FIPV strain 79-1146 and FECV strain 79-1683. Vet Microbiol 1991; 28: 13-24.

47 Vennema H. Genetic drift and genetic shift during feline coronavirus evolution. Vet Microbiol 1999; 69: 139-141.

48 Fehr D, Bolla S, Herrewegh AA, et al. Detection of feline coronavirus using RT-PCR: basis for the study of the pathogenesis of feline infectious peritonitis (FIP) [article in German]. Schweiz Arch Tierheilkd 1996; 138: 74-79.

49 Egberink HF, Herrewegh AP, Schuurman NM, et al. FIP, easy to diagnose? Vet $Q$ 1995; 17 Suppl 1: 24-25.

50 Addie DD. Clustering of feline coronaviruses in multicat households. Vet J 2000; 159: 8-9.

51 Addie D, Belak S, Boucraut-Baralon C, et al. Feline infectious peritonitis. $A B C D$ guidelines on prevention and management. J Feline Med Surg 2009; 11: 594-604.

52 Pedersen NC, Sato R, Foley JE, et al. Common virus infections in cats, before and after being placed in shelters, with emphasis on feline enteric coronavirus. J Feline Med Surg 2004; 6: 83-88.

53 Meli M, Kipar A, Muller C, et al. High viral loads despite absence of clinical and pathological findings in cats experimentally infected with feline coronavirus (FCoV) type $I$ and in naturally FCoV-infected cats. J Feline Med Surg 2004; 6: 69-81.

54 Korbie DJ and Mattick JS. Touchdown PCR for increased specificity and sensitivity in PCR amplification. Nat Protoc 2008; 3: 1452-1456.

55 Kipar A, May H, Menger S, et al. Morphologic features and development of granulomatous vasculitis in feline infectious peritonitis. Vet Pathol 2005; 42: 321-330.

56 Weiss RC and Scott FW. Pathogenesis of feline infectious peritonitis: nature and development of viremia. Am J Vet Res 1981; 42: 382-390.

57 IDEXX Reference laboratories. IDEXX Reference Laboratories now offers the Feline Infectious Peritonitis (FIP) Virus RealPCR ${ }^{\mathrm{TM}}$ Test to aid in the diagnosis of this devastating feline disease. Diagnostic Update. https:/ / www. idexx.com/files / small-animal-health/products-and-services / reference-laboratories / feline-infectious-peritonitisvirus.pdf (2014, accessed 24 February 2015).

58 Pedersen NC, Eckstrand C, Liu H, et al. Levels of feline infectious peritonitis virus in blood, effusions, and various tissues and the role of lymphopenia in disease outcome following experimental infection. Vet Microbiol 2015; 175: 157-166.

59 Soma T, Wada M, Taharaguchi S, et al. Detection of ascitic feline coronavirus RNA from cats with clinically suspected feline infectious peritonitis. J Vet Med Sci 2013; 75: 1389-1392.

60 Addie DD, Schaap IA, Nicolson L, et al. Persistence and transmission of natural type I feline coronavirus infection. J Gen Virol 2003; 84: 2735-2744.

61 Litster AL, Pogranichniy R and Lin TL. Diagnostic utility of a direct immunofluorescence test to detect feline coronavirus antigen in macrophages in effusive feline infectious peritonitis. Vet J 2013; 198: 362-366. 